\title{
Editorials
}

\section{Reflections at the Deep End}

After 12 journal articles from GPs at the Deep End, ${ }^{1}$ it is timely to reflect on the early progress and immediate future of the Deep End Project.

The Project has given group identity to the 100 general practices that serve the most severely deprived populations in Scotland. Scattered across 11 local NHS organisations, Deep End practices are a majority of practices in only two of these areas. Not only do most practices now know their rank in the top 100, the Deep End has also been mentioned by keynote speakers at national and international conferences, and cited in The Lancet2,3 and $B M J .{ }^{4}$ Correspondence from practices in England, Belgium, Ireland, and the US has given the Project an international dimension.

The first meeting in 2009, bringing together 67 Deep End GPs, was cathartic. ${ }^{5}$ Assembled for the first time in the 60-year history of the NHS, there was an instant bond. It may have helped that apart from three guests there were only GPs present. The group was immediately energised and positive.

Fourteen smaller meetings, costing about $€ 70000$ and involving 73 practices in total, were subsequently organised and reported, all within 14 months, reflecting the speed with which GPs can do things when they wish. ${ }^{6}$ Twelve Deep End GPs comprised the steering group. An informal alliance of colleagues from Glasgow University, RCGP Scotland, and the International Futures Forum provided support in kind.

\section{CAPTURING EXPERIENCE AS EVIDENCE}

The evidence that meetings sought to capture was the experience and views of practitioners working in the most deprived areas. These were rich discussions. It seemed that only a small number of GPs was sufficient to describe experiences that are common to many. Observers, such as policy advisors from the Scottish Government Health Directorate, were also enthused. Some were used to seeing GPs only across negotiating tables and had never witnessed GPs sharing and discussing the work they do. A note was taken of everything that was said, summary reports were written, and the contents and conclusions were checked with participants.

A key factor was the budget that allowed locum payments to be made and a wide range of practices to be represented. The Scottish Government funded three meetings, but most of the locum budget was obtained by serendipity. The Glasgow Centre for Population Health had funded the Primary Care Observatory Project,? describing the epidemiology of primary care based on general practice denominators, but the project had ended early after a key staff departure. Having described Deep End general practices in detail, the logical next step was to use the unspent funds to contact the practices directly. Fortunately, the funder agreed.

The jargon of public health, NHS management, and government health policy was notably absent. The issues were familiar but the language was different. Some flagship government health policies were barely recognised by Deep End GPs. Not only can the NHS be a Tower of Babel; its highest and bottom-most reaches can be worlds away.

The Deep End discussions had authority, however, with groups reflecting dozens and occasionally hundreds of years of collective experience of working in the front line, seeing patients, communities, and society as they are. A huge amount of knowledge had been acquired by practitioners and their colleagues. There was frustration at not being able to apply such knowledge, especially in relation to at risk families, and anger when such knowledge had been casually thrown away via redeployment or loss through burn out of attached nursing staff.

\section{HEALTH CARE AS A SOCIAL \\ DETERMINANT OF HEALTH}

Meetings took for granted, indeed affirmed, the value of general practice, improving population health not only via the mass delivery of evidence-based medicine but also via the unconditional, personal, continuity of care provided for all patients, whatever condition or combination of

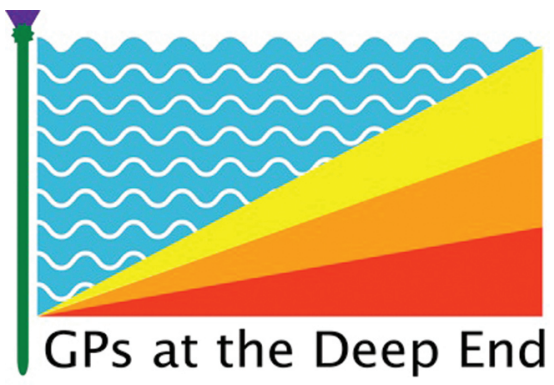

conditions they present. The contribution of general practice to improving health and narrowing inequalities in health is not so much via the learning of new tricks and delivery of externally devised toolkits, as by increasing the volume and quality of what Deep End practices do.

Work in the Deep End is dominated by the number, severity, and complexity of health and social problems within families and the difficulty of addressing such problems in short consultations. ${ }^{8}$ In a survey of GP trainees in Deep End practices, one of their concerns was exposure to the worried well'. They had heard and read about such patients, but had not come across them in the Deep End.

Everyone understands that the social determinants of poor health are deeply rooted and difficult to address, but health care is also a social determinant of health and could do much more. Deep End practitioners would like health policies that value and support long-term commitment.

\section{ADDRESSING THE INVERSE CARE LAW}

Having raised the profile of the Deep End, what next? Will it be a flash in the pan, adding to the innumerable land thus, by definition, largely ineffective) reports, plans, and policies addressing inequalities in health?

There is a huge opportunity. Deep End practices achieve as many points in the Quality and Outcomes Framework as other practices; 45 practices teach undergraduates; 46 take part in research; 


\section{"In a survey of GP trainees in Deep End practices, one of their concerns was exposure to 'the worried well'. They had heard and read about such patients, but had not come across them in the Deep End.}

67 took part in the activities of the Scottish Primary Care Collaborative; $61 \%$ of the 335 Deep End GPs have the MRCGP or FRCGP The inverse care law in Scotland is not explained by good practices in affluent areas and bad practices in deprived areas; rather it is the difference between what Deep End practices can do and could do if supported to address unmet need.

Addressing the inverse care law is not rocket science. The problems are time and links. NHS Scotland is well placed to demonstrate what universal coverage and needs-based services can achieve. Of course, targeting only the most deprived areas is insufficient. What is needed in the Deep End is also needed in less deprived areas, serving pocket rather than blanket deprivation, on a pro rata basis according to the principle of proportionate universalism. ${ }^{9}$

GPs at the Deep End cannot solve the inverse care law on their own. Three other essential ingredients are first, political commitment land lack of professional opposition) to the NHS being at its best where it is needed most; second, national support for the scattered front line; and third, re-alignment of local NHS resources, services, and structures to support general practice hubs.

Wheels are beginning to turn. A randomised controlled trial of extra time for consultations for patients with multiple morbidity is underway. The Links project has explored Deep End practice's knowledge and use of non-medical community resources and has led to a new project, promoting wellbeing and delaying disability in older patients in Deep End practices. Proposals are being drawn up to pilot attached mental health and addiction workers, and to involve Deep End practices in policies for the Early Years Framework..$^{10}$ A second national meeting is planned for March 2012, with Government funding.

GPs at the Deep End are on a new trajectory. We do not know where it will end, but it is good to be marching on the right road. As Robert Louis Stevenson wrote:

'... to travel hopefully is a better thing than to arrive, and the true success is to labour.'.

\section{Graham Watt,}

Professor of General Practice, General Practice and Primary Care, Institute of Health \& Wellbeing, University of Glasgow, Glasgow.

\section{Provenance}

Commissioned; not externally peer reviewed.

DOI: 10.3399/bjgp12X616210

\section{ADDRESS FOR CORRESPONDENCE}

\section{Graham Watt}

Institute of Health \& Wellbeing, General Practice \& Primary Care, University of Glasgow, 1 Horselethill Road, Glasgow, G12 9LX, UK.

E-mail: Graham.Wattaglasgow.ac.uk

\section{REFERENCES}

1. Watt G. General Practitioners at the Deep End 12 articles in the British Journal of General Practice 2011; 61: 66-67, 146, 228, 298, 350, $407,463,519,569,629,685$ and 741 .

2. MacAuley D. Floundering in the deep end reflections on the RCGP conference. London: BMJ, 2011.

http://blogs.bmi.com/bmj/2011/10/27/domhnal l-macauley-floundering-in-the-deep-end laccessed 24 Nov 2011).

3. Horton R. Offline: face to face, side by side. Lancet 2011; 377(9773): 1224

4. Horton R. Offline: 8 minutes. Lancet 2011; 378(9802): 1538.

5. Alaxander P, Budd J, Sambale P, Watt G. General Practitioners at the Deep End. Final report of a special meeting held on 16 September 2009 at Erskine Bridge Hotel. Glasgow: University of Glasgow, http://www.gla.ac.uk/departments/generalpra cticeprimarycare/deepend laccessed $24 \mathrm{Nov}$ 2011).

6. Alaxander P, Budd J, Sambale P, Watt G. Reports of meetings 2-15 of general practitioners at the Deep End. http://www.gla.ac.uk/departments/generalpra cticeprimarycare/deepend laccessed $24 \mathrm{Nov}$ 2011)

7. Watt G. Connecting with general practice to improve public health. Report of the primary care observatory and Deep End projects. Glasgow: Centre of Population Health, 2011. http://www.gcph.co.uk/publications/277_gps_a t_the_deep_end laccessed 24 Nov 2011).

8. Watt $\mathrm{G}$. The inverse care law today. Lancet 2002; 360(9328): 252-254

9. Commission on Social Determinants of Health. Closing the gap in a generation: health equity through action on the social determinants of health. Final report of the commission on social determinants of health. Geneva: World Health Organization, 2008.

10. The Scottish Government. The Early Years Framework. Edinburgh: Scottish Government, 2008 